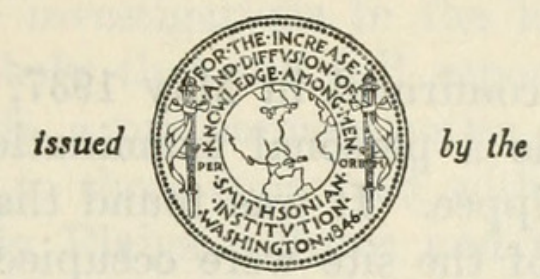

SMITHSONIAN INSTITUTION

U. S. NATIONAL MUSEUM

\title{
HOPEWELLIAN REMAINS NEAR KANSAS CITY, MISSOURI
}

\section{By Waldo R. Wedel}

EarLy in February 1937, the Bureau of American Ethnology was notified of an Indian village site in Platte County, Mo., about 5 miles northwest of Kansas City. The information was shortly communicated to me, since at the time I was formulating plans for field work in nearby northeastern Kansas as the initial step in a projected State-wide archeological survey. According to the correspondent, J. M. Shippee, of North Kansas City, the site was located on Line Creek, a small formerly perennial stream falling into the Missouri from the north about midway between Kansas City and Parkville. Though long known to local collectors of surface relics, its possibilities were not realized until recent pipe-line and highway construction had revealed cultural material to a depth of 2 feet or more. Aside from the fact that no village sites in this locality had ever been systematically excavated and described, it was also noted that on the wooded bluffs just east of the village were located the Brenner, Klamm, and Keller mound groups. Excavated many years ago and described by Fowke and others, ${ }^{1}$ some of these mounds have been found to contain stone-walled burial chambers, but their cultural identity has never been established. Upon request, sketches and descriptions of the pottery fragments and other remains on the nearby village site were furnished us, and it was at once suspected that the complex represented therein was

${ }^{1}$ Fowke, Gerard, Antiquities of central and southeastern Missouri. Bur. Amer. Ethnol. Bull. 37, pp. 65-73 and references, 1910. 
very unlike any heretofore described from the Plains or the Missouri Valley.

This suspicion was confirmed in May 1937, when I proceeded to Kansas City and made a personal examination of the remains in company with Mr. Shippee. It was found that the most promising undestroyed portions of the site were occupied by the owner's residence, garage, poultry yard, and garden. Permission to excavate was nevertheless unhesitatingly granted by the owners, Mr. and Mrs. Leslie Renner, who had previously and have since protected the site against vandalism, besides extending to us at all times the utmost courtesy and cooperation despite the inconvenience to which they were put. Investigations, in which I was assisted by four students, subsequently covered the entire month of June. Through the good services of Ralph Henneman, another interested collector, and the kindness of Transcontinental Western Air and United States Bureau of Air Commerce officials, we were enabled to supplement our records with an aerial reconnaissance of the site and its surroundings.

The Renner site, so named after the owners, is situated on a small terrace on the right bank of Line Creek about a mile north of the Missouri River. It covers an area of about 5 acres, immediately below the junction of Juntin Branch and Line Creek, just before the latter emerges from the bluffs zone to cross the alluvial river bottoms. Riverside Racetrack is nearby to the south. The bluffs east and west of the site rise to heights of 150 feet or more and are still partially covered with oak, ash, elm, walnut, hickory, and other hardwood species. To the north is the attractive and fertile Line Creek Valley, in which are other old villages as yet unexplored.

The new road, on U. S. Highway 169 between U. S. 71 and Missouri State Highway 45, cut a strip nearly 100 feet wide across the center of the site. In the roadside cross sections there had been revealed a dark soil zone extending from the ground surface to a depth varying from 13 to 30 inches. Below and usually sharply separated from this dark stratum was bright yellow clay subsoil. Numerous potsherds, burnt limestone boulders, animal bones, and flints occurred throughout the upper layer and appeared to be especially plentiful in and near pits that extended to depths as much as 6 feet below the present ground surface. Unquestionably, great quantities of cultural material were destroyed in building the highway, but through courtesy of the superintendent of construction, H. M. Kleifeld, most of what had been rescued was presented to us for the national collections. 
Up to the present, no detailed studies of our findings have been made. Since further investigations in the locality are now under consideration, it is likely that the full report will be delayed for some time. Meanwhile, a preliminary notice of the remains may be of interest, especially to those concerned with determining the relationship between early Plains cultures and the archeological complexes found in the Eastern United States. Such generalizations as may be suggested here are subject to revision in the light of more intensive analyses and further field investigations.

Our excavations were confined to the remaining part of the site lying east of the new road, between it and the creek bottoms. Here over an area of about 3,000 square feet the cultural layer was stripped off by troweling until subsoil was reached, at which level the pits showed as dark trash-filled circular spots. Thirty-six of these were opened, averaging about 3 feet in diameter and $21 / 2$ to more than 5 feet in depth. Originally these were probably used for storage of foodstuffs, but most of them yielded only refuse and a few artifacts. Noteworthy among their contents, aside from artifact materials, were charred maize, beans, pawpaw seeds, and several species of nuts, as well as quantities of mammal, bird, and fish bones. Bulk of the mammalian remains were apparently of the deer, but there is evidence also of the bison. No postholes, firepits, or other traces of houses were noted, although there were numerous large and small chunks of baked brick-red clay of unknown purpose. It is inferred that the habitations must have been entirely of perishable materials rather than of the substantial earthlodge type used by many tribes and peoples of the Missouri Valley. There is some slight evidence for the former existence of refuse mounds, but mostly the detritus now occurs either in the pits or as admixture in the old living surface of the village.

Potsherds were found in great abundance everywhere on the site. It was at first thought that these represented two distinct types, but more careful scrutiny suggests the presence of intergrading specimens. At one extreme are coarse, thick, gravel-tempered sherds with cord-roughened exteriors. These apparently are from large pointedbase jars, none of which have yet been actually reconstructed. Below the squared lip is usually a row of embossed nodes, punched outward from the interior, and above these may or may not be found the vertical or diagonal imprints of a small cord-wrapped stick or a dentate implement (pl. $3, G)$. Other large similarly shaped vessels, also bearing the bosses but with plain neck and rocker-roughened body decoration, are indicated (pl. 3, $F, H, I$ ). The heavy gravel-tempered pointed-base jars, with cord-roughening and punched bosses, are strikingly reminiscent of sherds found at sev- 
eral deeply buried sites in eastern Nebraska, where they apparently represent the earliest known ceramic horizon.

Greatly superior in quality and decorative technique are many sherds of a type heretofore unrecorded this far west. Here gravel or grit tempering is again universal, but it is more sparingly used and of finer texture. Vessels were small to medium in size (up to 1 or possibly 2 gallons capacity), with thin walls and slightly constricted necks. Rim profiles show a more or less pronounced channel or groove on the inside, an inward-beveled lip, with cross-hatched (or rocker-marked) and punctate decoration on the outer surface (pl. 3, $A-D)$. This ornamentation also occurs on some fragments of the larger, rougher jars of the preceding type, where the zones of cross hatching and punctates are occasionally separated by a row of embossed nodes. From the restorable vessels and larger sherds it is evident that the neck in this second type of ware was usually a plain smoothed band, separated by a wide incised line or groove from the ornamented body. Decoration on the body usually consisted of rocker-roughening, sometimes with scroll or other curvilinear designs worked out in alternate smooth and roughened bands separated by narrow to wide shallow grooves (pl. 6, B). One incomplete jar was evidently square with rounded corners, each of the latter being rocker-roughened (pl. 5, $H$ ). A few sherds suggest use of a dentate tool such as the roulette (pl. $3, E)$, but the majority were impressed with a smooth rocker. Many body sherds bear no decoration whatever. In most respects this ware closely approaches the so-called Hopewellian type, but the body ornamentation is somewhat less intricate and the roulette or dentate stamp technique apparently less common than on pottery from the classic sites farther east. ${ }^{2}$

It is possible that detailed counts of the several thousand potsherds recovered will reveal some variation in the relative frequency of the several sherd types at different depths. Such variation, if it exists, is not now apparent, and it was definitely noted that the various types occurred together in a number of the pits as well as side by side throughout the culture stratum.

Of unusual interest is a portion of a smoothed bowl bearing rocker-roughened designs suggestive of a conventionalized hand (pl. $6, A)$. Originally there were apparently four of these decorative units encircling the vessel, each inclosed by a broad incised line. Miniature pottery, including the bowl of a tiny ladle, a crude bird effigy (pl. $4, H$ ), and a few pieces possibly representing human or animal heads were found.

${ }^{2}$ Setzler, Frank M., Pottery of the Hopewell type from Louisiana. Proc. U. S. Nat. Mus., vol. 82, art. 22, pp. 1-21 and references under footnote $1,1933$. 


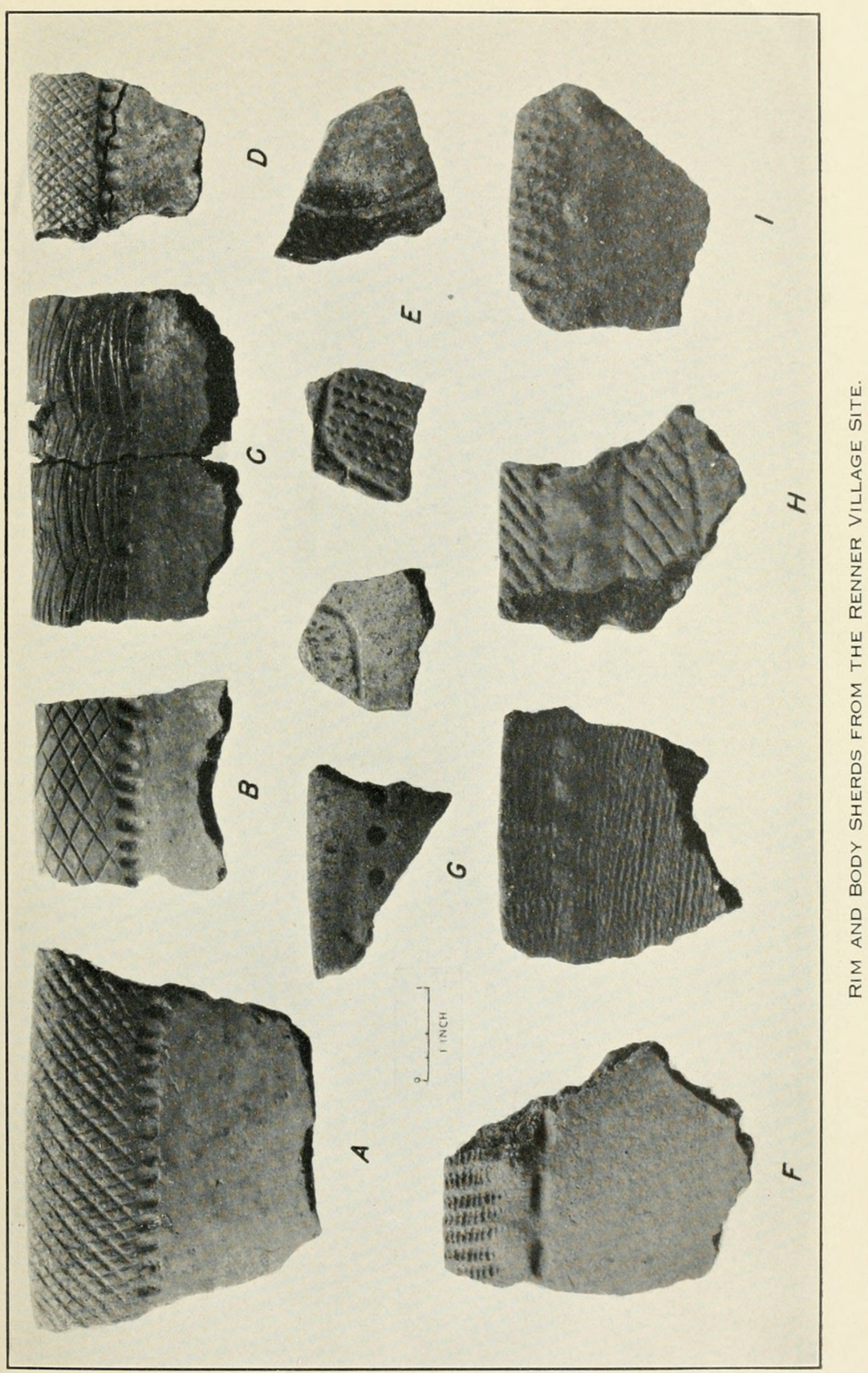




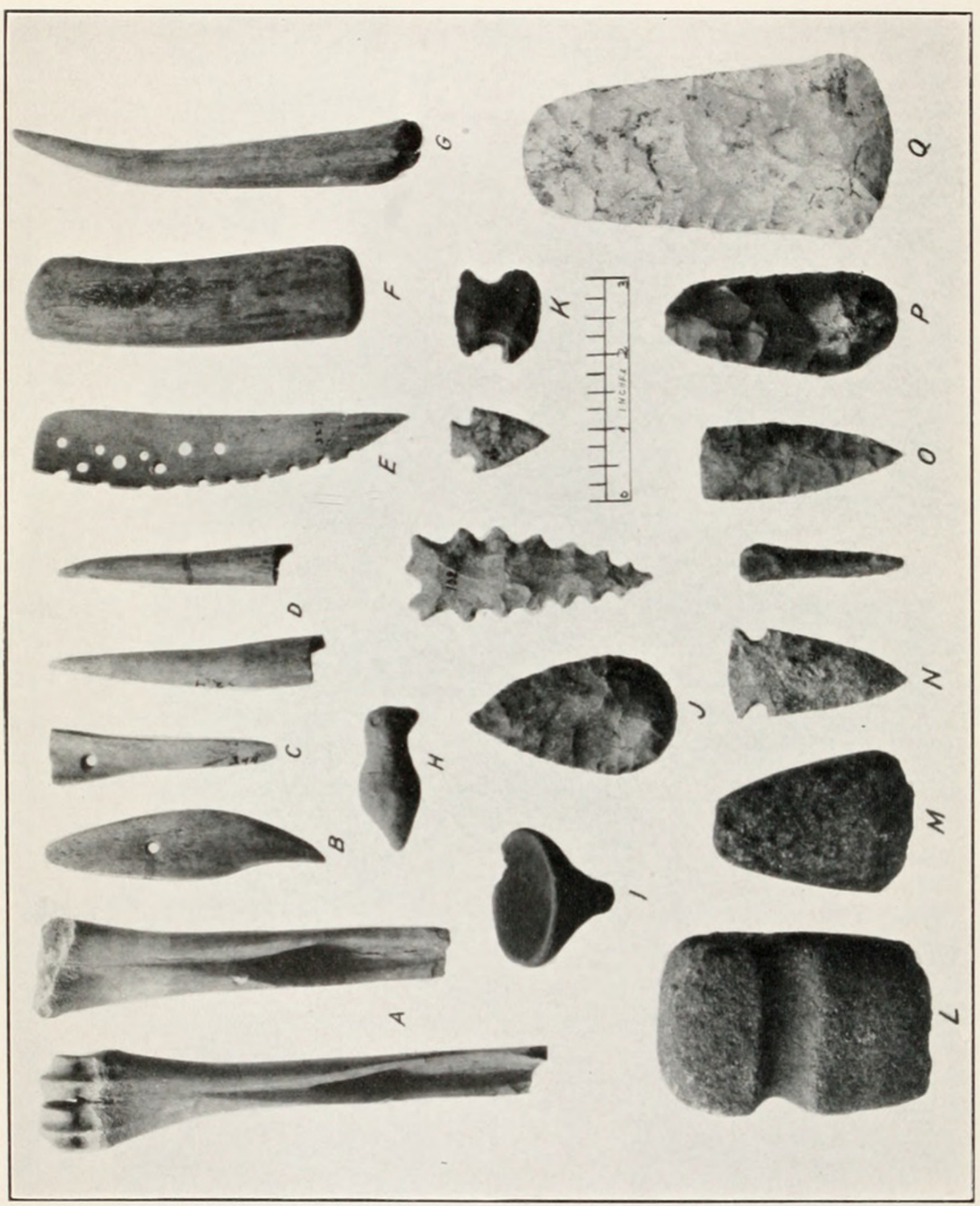

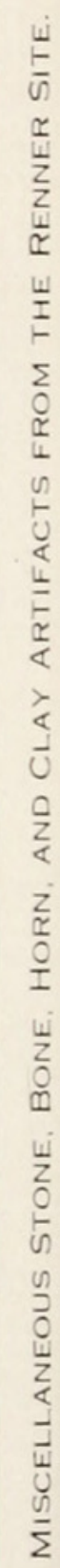




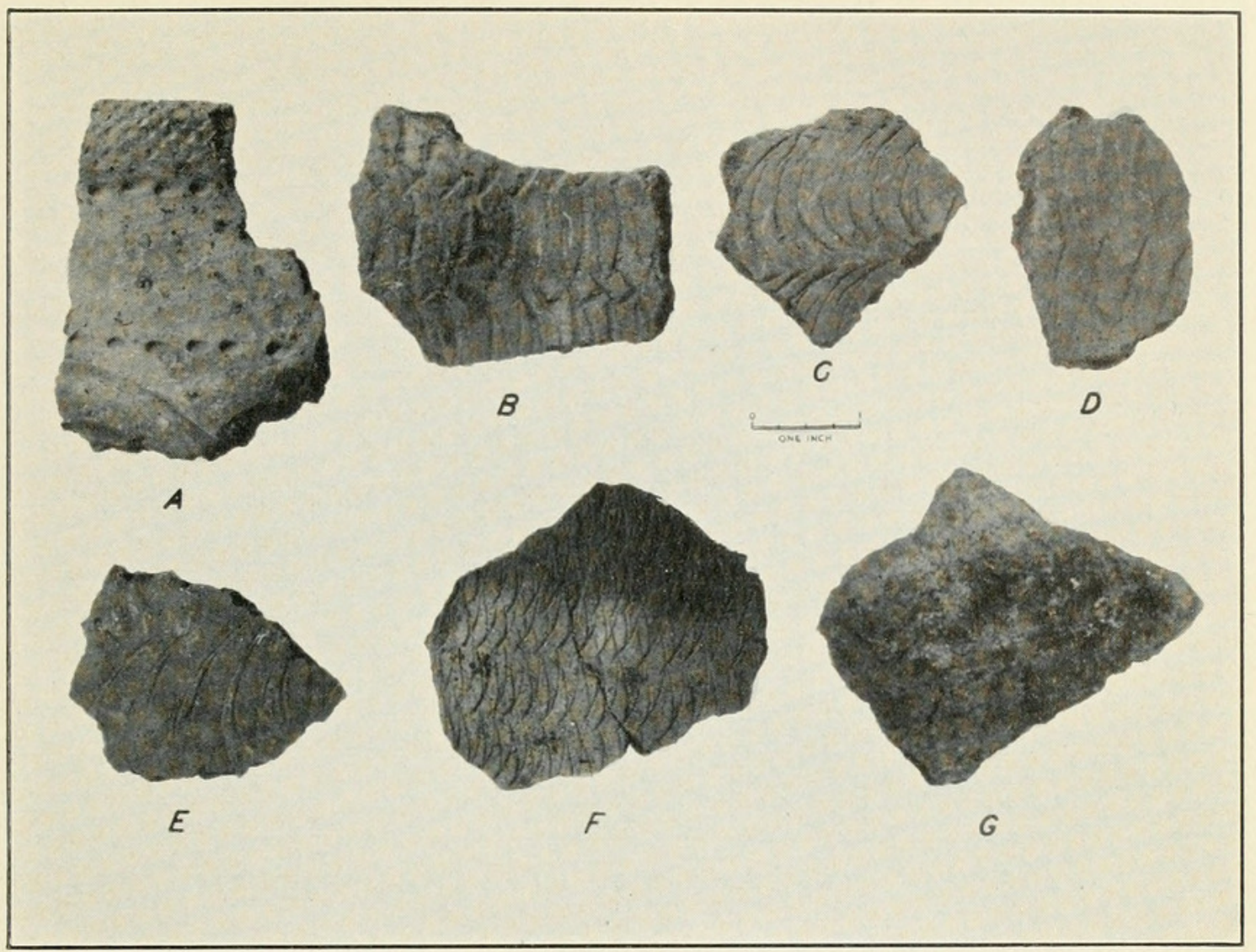

POTSHERDS FROM THE RENNER SITE.

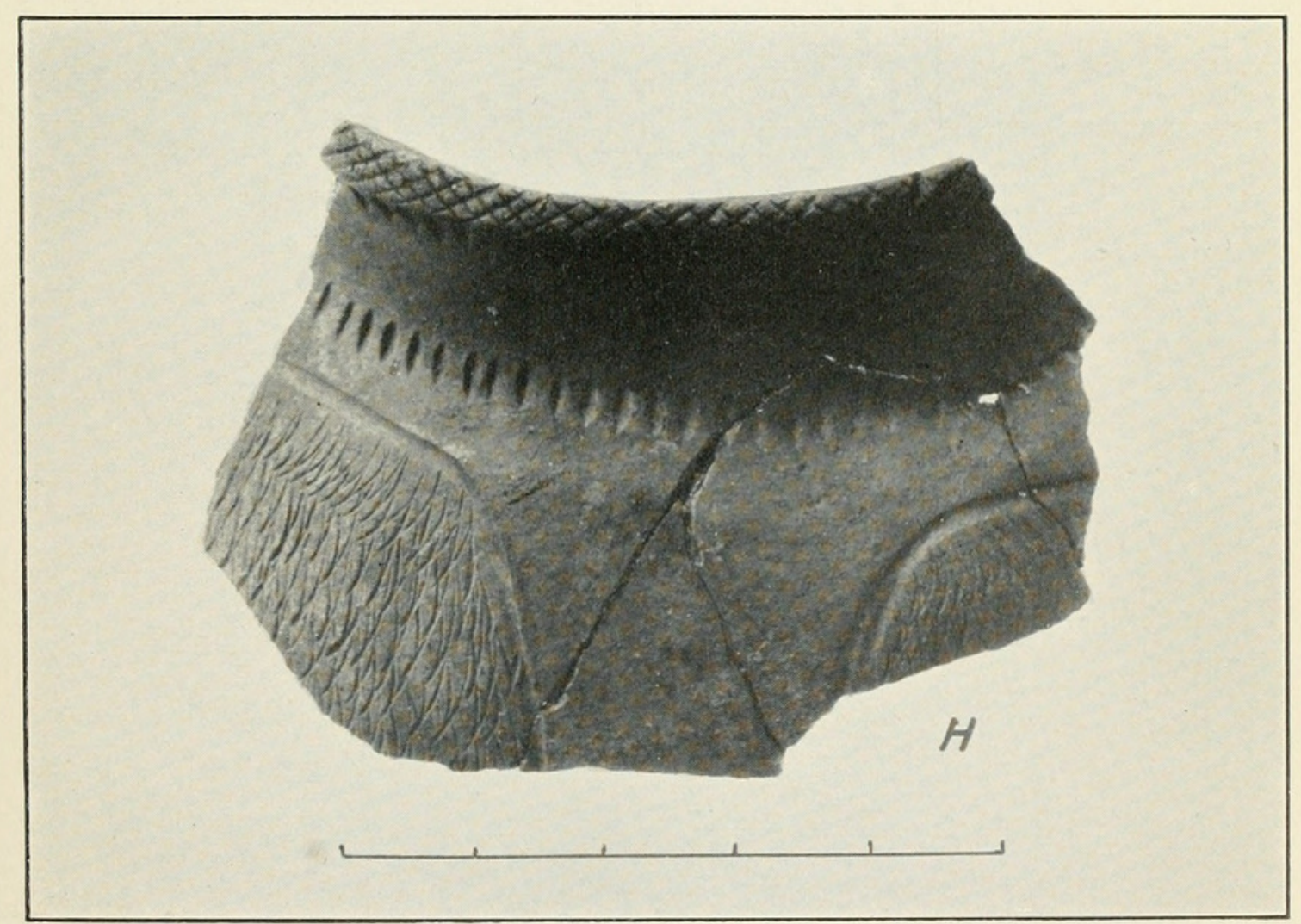

PORTION OF SQUARE VESSEL WITH ROUNDED CORNERS FROM THE RENNER SITE. (Scale: 5 inches.) 


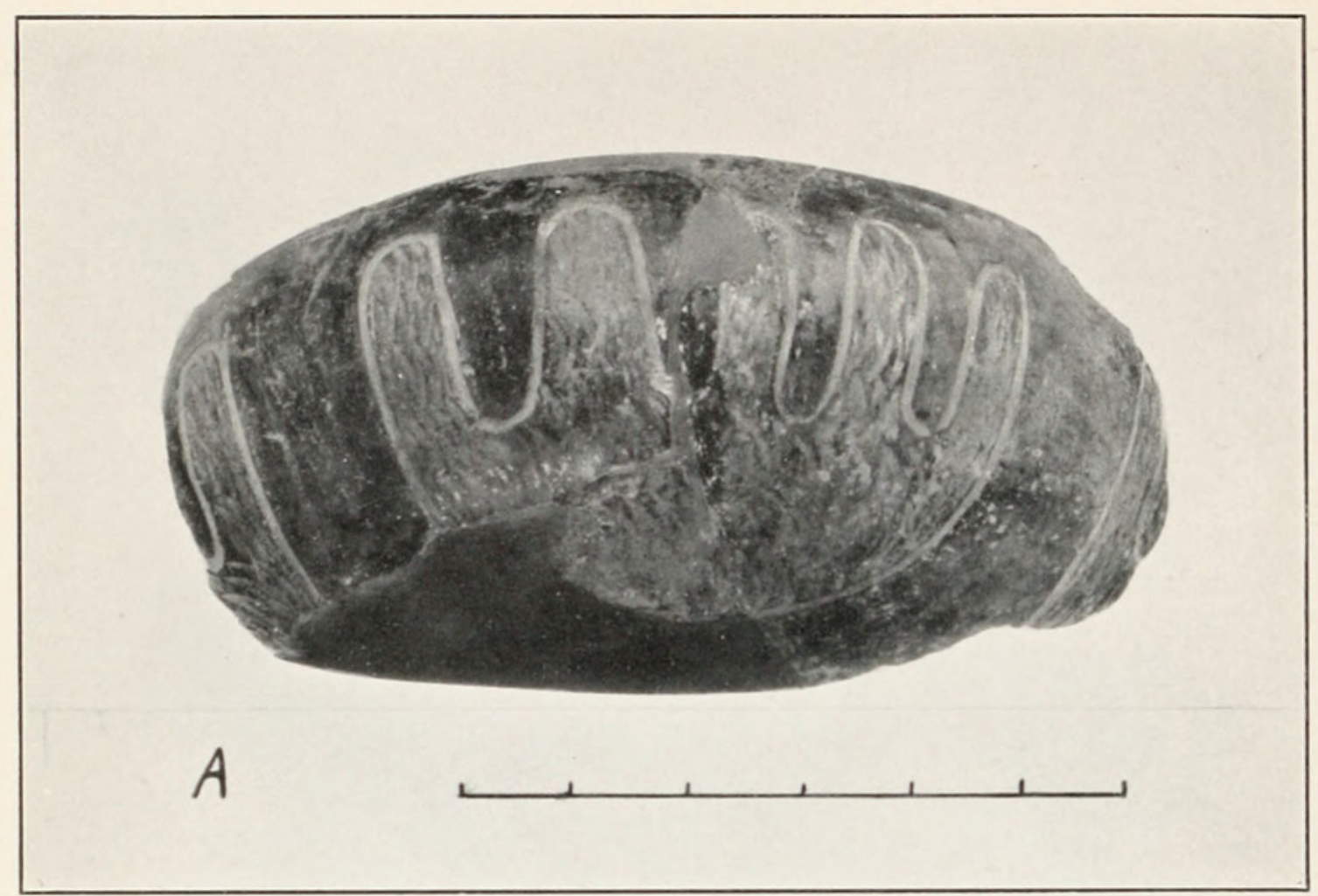

PORTION OF DECORATED BOWL FROM THE RENNER SITE.

(Scale: 6 inches.)

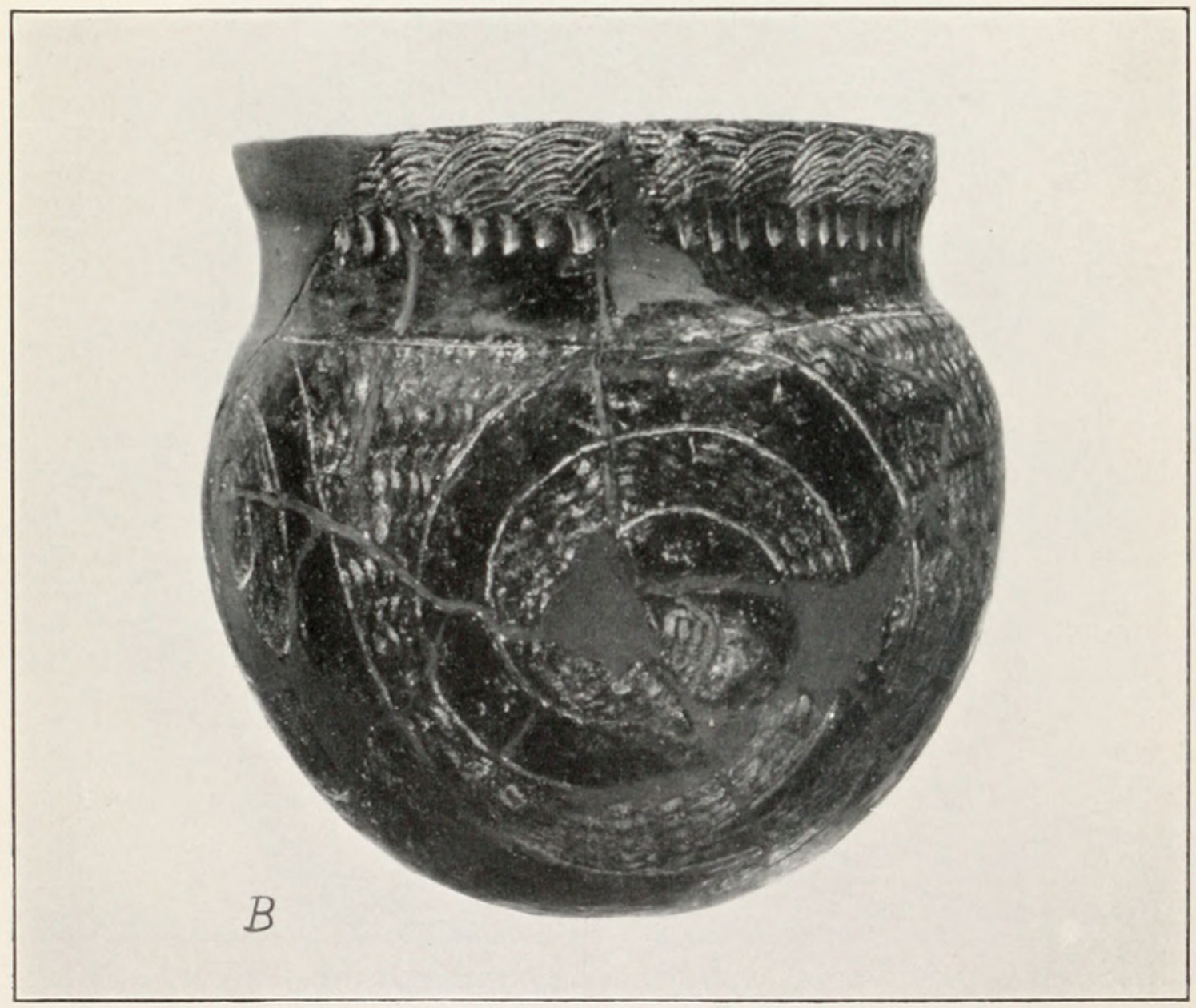

RESTORED VESSEL FROM THE RENNER SITE.

(Height, 61/2 inches; diameter, 61/2 inches.) 


\section{$2 \mathrm{BHL}$ Biodiversity Heritage Library}

Wedel, Waldo R. 1938. "Hopewellian remains near Kansas City, Missouri." Proceedings of the United States National Museum 86(3045), 99-106. https://doi.org/10.5479/si.00963801.86-3045.99.

View This Item Online: https://www.biodiversitylibrary.org/item/32496

DOI: https://doi.org/10.5479/si.00963801.86-3045.99

Permalink: https://www.biodiversitylibrary.org/partpdf/10641

\section{Holding Institution}

Smithsonian Libraries

\section{Sponsored by}

Smithsonian

\section{Copyright \& Reuse}

Copyright Status: NOT_IN_COPYRIGHT

Rights: https://www.biodiversitylibrary.org/permissions/

This document was created from content at the Biodiversity Heritage Library, the world's largest open access digital library for biodiversity literature and archives. Visit BHL at https://www.biodiversitylibrary.org. 